\title{
Construction of the integrated model for practical career support to the professional athletes
}

\author{
${\text { Motoki Mizuno a, }{ }^{\text {, }} \text {, Yasuyuki Hochi }}^{\text {a }}$, Mami Inoue ${ }^{\mathrm{b}}$, Ikuyo Kaneko ${ }^{\mathrm{c}}$, Yasuyuki Yamada ${ }^{\mathrm{d}}$ \\ ${ }^{a}$ Juntendo University Graduate School of Health and Sports Science, Japan \\ ${ }^{\mathrm{b}}$ Hitachi Brain Co.,Ltd., Japan \\ ${ }^{\mathrm{c}}$ Juntendo University School of Health and Sports Science, Japan \\ ${ }^{d}$ Nagoya City University Graduate School of Medical Sciences, Japan
}

\begin{abstract}
Recently, along with the enhancement of the argument for career of athletes, many researchers who major in sports psychology focus mainly on athletic retirement, a coordination of transitions in sport or and outside sport, social support and professional assistance in career transition, in the context of the second career concerning to professional athletes in Japan. However, when it comes to career transition of professional athletes, it is necessary to consider "career" from the whole perspectives of human life. Therefore, the purpose of this study is to clarify the career transition of professional athletes by the way of questionnaire and interview survey, which is approached from the view point of industrial/organizational psychology. For this purpose, we implemented the interview survey to professional athletes in 2008. In addition, we carried out the investigation to professional football players (interview survey: 5 players, questionnaire survey: 102 players) in 2009. Consequently, three following findings were led in conclusion. (1)Career intervention to professional athletes should be performed before the turning point of the career (career transition). (2)It is important to assess the career intervention to professional athletes. (3)It is an important stance to watch the processes when professional athletes open up one's career by oneself.
\end{abstract}

Keywords: professional athletes, career support, second career, career intervention, career development

\section{Introduction}

Recently, along with the enhancement of the argument for career of athletes, the necessity of the study on career design of athletes has increased incrementally. In the sports organization, it is important to bring up the athletes who can design life career plan after the retirement with professional consciousness. Therefore, for an opportunity of the career transition called the competition retirement to come before long, it is said that it is necessary to push forward preparations by oneself. In addition, for the athlete who gave most of the conventional life career to competition life, as for the career transition from a athlete to a non-athlete, it may be said that the way of the career support that enable to enter the new field until the mental health management of the athletes in future is demanded because it can be a serious stressor to bring a lubricity. Therefore, the purpose of this study was to obtain the viewpoint of more practical career support by understanding the career of professional athletes from three perspectives in a gross.

\section{Practice innovation (methods)}

(1)Interview survey was carried out targeting to a professional baseball player and a J League player (football) from June to May in 2008. And (2)career anchor theory of Schein(1975) was used to clarify substance of the career awareness of the professional athletes in questionnaire survey. Moreover, (3)to clarify the importance and the career maturity of each skill at the period of career transition, the interview

'Corresponding author. E-mail: m-mizuno@sakura.juntendo.ac.jp 
survey was carried out targeting to 5 JFL (Japan Football League) players from September to October in 2009 and questionnaire survey was implemented for 102 JFL players from May to April in 2009.

\section{Findings and Discussion}

According to three investigations mentioned above, three following findings were led in conclusion. (1) It was revealed that professional athletes had much uneasiness at the period of career transition before acquiring the next new role. (2)Career anchors of professional athletes during career transition could be integrated, and it was confirmed that plural career anchors were moved around in oneself. Therefore, the significance of examining the way of concrete career support to each player from the viewpoint of career anchor and role exit theory was proved. (3) As career transition period advanced to latter period, it was confirmed that each skill became higher. Besides, it was revealed that career maturity became higher in order of "technical skill", "human skill", "conceptual skill". Furthermore, in conjunction with a time change with the career transition, it was confirmed that the importance and the career maturity of each skill became higher. Three theories called career development, career awareness, career maturity created the following conclusions at least. (1)Career intervention to professional athletes should be performed before the turning point of the career (career transition) because much uneasiness occurs for the shift period of the career stages of development. (2)It is important to assess the career intervention to professional athletes because individual differences were remarkable. (3)It is an important stance to watch the processes when professional athletes open up one's career by oneself because their career skills improve along with career development.

\section{References}

[1] Inoue, Mami, Motoki Motoki, Yamada Yasuyuki : A study on consciousness of career planning among professional football players in Japan, Proceedings of International Ergonomics Association, CD-ROM.(2009).

[2] Mizuno, Motoki, Business Management Approach to Career Transition of Athletes, The $32^{\text {nd }}$ Annual Conference Proceedings of Japanese Society of Sports Psychology, 2005, pp.8-9. (in Japanese)

[3] Mizuno, Motoki, Theoretical Perspectives of Career of Athletes, The $33^{\text {rd }}$ Annual Conference Proceedings of Japanese Society of Sports Psychology, pp.188-189. (2006), (in Japanese)
[4] Mizuno, Motoki et al., A Study on Career Transition and Psychological Stress of University Atheletes, The $58^{\text {th }}$ Conference of Abstracts of Japan Society of Physical Education, Health and Sport Sciences, p.175. (2007), (in Japanese)

[5] Mizuno, Motoki et al., what is the meaning of consideration of career transition of professional athletes?: From the view point of human ergology, The News Letter of Human Ergology, No.88, pp.20-21. 175. (2008), (in Japanese)

[6] Mizuno, Motoki, Masayuki Yamada, Mami Inoue, Yasuyuki Yamada : Human Ergological Approach to Career Transition of Professional Athletes in Japan, Proceedings of International Ergonomics Association, CD-ROM.(2009).

[7] Schein, Edgar. H. "How career anchors hold executives to their career paths," Personnel, 52; 11-24.(1975).

[8] Schein, Edgar. H., Career Anchor: Participant Workbook(3 $3^{\text {rd }}$ ed.) Pfeiffer\&Co.(2006).

[9] Yamada, Yasuyuki, Motoki Mizuno, Masataka Hirosawa : The fundamental study of stress improvement in university athlete. The $5^{\text {th }}$ international symposium of Juntendo university (2009).

[10] Hochi, Yasuyuki, Yasuyuki Yamada, Motoki Mizuno: Effects of Organizational Development on the Psychological Aspects among University Students. International Conference for the 40th Anniversary of Human Ergology Society Program and Abstracts, pp39-40.(2010)

[11] Yamada, Yasuyuki, Motoki Mizuno, Yasuyuki Hochi: Does Organizational Development bring the Change of SelfUnderstanding among University Students? 25th Annual Meeting of the Japanese Association of Industrial and Organizational Psychology. pp.91-94. (2009) (in Japanese) 